\title{
The new sociology of species and media: a review
}

Media, Culture \& Society

C) The Author(s) 2017

Reprints and permissions:

sagepub.co.uk/journalsPermissions.nav DOI: $10.1177 / 0163443717706072$

journals.sagepub.com/home/mcs

@SAGE

\author{
Núria Almiron, Matthew Cole and Carrie P Freeman (eds), Critical Animal and Media Studies: \\ Communication for Nonhuman Animal Advocacy. New York: Routledge, 2016.
}

Although the burgeoning study of 'animals and society' has demonstrated that Nonhuman Animals ${ }^{1}$ are heavily embedded in human societies, institutions, and systems, the sociological discipline has been overwhelmingly silent on these relationships (Nibert, 2003; Peggs, 2013; Wrenn, 2016). When other animals are mentioned, it is primarily as food stuffs, environmental contagions, or tributary characters in human development. They remain absent referents in this sense - objects but never subjects (Adams, 2015). The same can be said of critical media studies despite its fundamental interest in exposing hidden economies of media dissemination, interpretation, and influence. Human animals may be the only species responsible for media construction, but they are certainly not the only to be depicted or impacted. Media has real-world consequences for Nonhuman Animals who are represented (or invisibilized) on screen or page, and, invariably, these consequences impact humans as well. For the literature to remain silent on these connections is a disservice to the discipline of scientific inquiry and critical thought.

Critical Animal and Media Studies (Routledge 2016) addresses this gap in coalescing the work of established and emerging British and American sociologists and interdisciplinary media scholars. Full of rich examples of Nonhuman Animals in human media that are both contemporary and classic, this compilation offers a nuanced entry point into the critical study of other animals in media spaces. There is also a careful presentation of introductory Nonhuman Animal rights and intersectionality theories, making this text valuable for critical media scholars who lack this background. The first section on theoretical foundations is perhaps the most useful for the uninitiated. These chapters feature the seminal work of Carol J. Adams on the entanglement of sexism and speciesism, David Nibert on the social construction of speciesism through media and capitalism, and Joan Dunayer on the maintenance of nonhuman oppression in language are the keystones. Adams, Nibert, and Dunayer are prolific and highly influential authors in the field of Critical Animal Studies (CAS), and their contributions here succinctly summarize their work such that Critical Animal and Media Studies (CAMS) will remain a staple reference to researchers.

In the spirit of Adams, Nibert, and Dunayer, the sociological theory offered by other contributors invites CAS scholars to explore the political economies of media production. Almiron's chapter on Big Food and the 'knowledge-interest nexus', for instance, is 
essential for any vegan researcher or activist wanting for a structural analysis of speciesism. CAMS attests that media is not simply a reflection of existing values and attitudes. Instead, it is strategically crafted and consciously manipulated by those in power with the express interest in protecting that power. The news is 'agenda-setting' and it 'rarely sets the agenda' in favor of animals (Freeman, 2016: 181).

While hegemony controls media production, it does not necessarily control interpretation. Nor can it necessarily eradicate competing perspectives. To this, CAMS adheres to an explicitly vegan approach, pushing even the most critical of scholars to reexamine their privilege as writers, journalists, and citizens. Consider Malamud's chapter on the dangers of the human gaze. While much has been pondered on the unequal relationship between the viewed and the viewee in human groups (Sassatelli, 2011), few take notice of the routinized representation of Nonhuman Animals as cartoons, clowns, villains, victims, 'meat', or other fetishized objects. Rarely are Nonhuman Animals presented with dignity. Malamud (2016) explains,

The practice of consuming visual culture embodies an unbridled omniscient lust ensuring the visual object's absolute subalternity. The animal is rendered vulnerable, free for the taking, in whatever way the human viewer chooses: the process metaphorically reiterates what is enacted literally in the culture of carnivorous agribusiness. (p. 158)

Even seemingly benign 'nature' documentaries recreate this domination in constructing a world eternally open to human audiences with narratives that are overwhelmingly designed to suit human desires and reinforce species inequality. When other animals are captured in image, they are captured in human hierarchies as well (Malamud, 2016).

This research is designed to be directly applicable for activist-scholars and social justice advocates looking beyond the page to manifest change in the world. A chapter contributed by Loy, for instance, identifies the power of cinema in persuading change with an examination of popular films. Stirring movies can presumably encourage audiences to acknowledge the narratives of speciesism that are otherwise obscured from human culture. Likewise, Friedman's submission identifies a double-edged sword in the media's coverage of Nonhuman Animal rights litigation. This is demonstrated with the case of kangaroo flesh peddled illegally for the production of high end sports shoes in America. Friedman found that news outlets were overwhelmingly biased in favor of speciesist industry. Perhaps most usefully, Freeman and Merskin outline a style guide for journalists to overcome these institutionalized barriers. The guide is specifically geared to reporters and writers hoping to advance Nonhuman Animal interests and challenge the status quo speciesist coverage.

Unfortunately, because the modern Nonhuman Animal rights movement is relatively young and anti-speciesist attitudes remain foreign to many Westerners, these praxisoriented contributions remain largely untested and unquantifiable. Chapters that examined content were strong, while chapters that made claims as to the impact of this content were wanting. Content analysis can reliably identify what is presented by the media, but content analysis is not appropriate for determining its impact on human behavior. Claims of this kind would require rigorous experimental research. Most CAMS contributors are not learned in the discipline of social movement theory, taking the media tactics 
of nonprofit organizations as factually persuasive while providing limited evidence in support of their effectiveness. Notably, Friedman's position that single-issue legal advocacy is a useful means of advancing Nonhuman Animal interests is a contested one that lacks empirical support (Wrenn, 2016). Likewise, Linné's chapter examines media in the classroom as a means of emotionally shocking students into action, but it was based on his personal reflection of two university classes and student feedback. The feedback is too limited to contend with the scientific uncertainty surrounding morally shocking imagery as an effective persuasion tool (Wrenn, 2013). Indeed, Taylor's chapter, 'Suffering is Not Enough', is directly critical of moral shock tactics. As a longtime researcher in domestic violence advocacy, Taylor warns that watching images of suffering can spark action in some cases, but there is potential for backfire. When suffering turns spectacle, the divide between the viewer and the viewee is aggravated. Legal advocacy and moral shocks are utilized by nonprofits with a focus on fundraising, not radical social change (Wrenn, 2013, 2016). An acknowledgment of this capitalist influence and conflict of interest in nonprofit praxis is lacking in $C A M S$.

While interpretation is sometimes biased in favor of neoliberal nonprofit advocacy, those chapters which rely on the systematic analysis of Nonhuman Animal representation are reliably useful in identifying patterns of representation. However, some of these analyses are so case specific that they risk becoming repetitive to those already familiar with the field given their limited theoretical advancement. These case-specific chapters can also be confusing to those unacquainted to the medium in question. For instance, a chapter on British comedy was lost on myself as an American, and much of the discussion on American television networks would be difficult for the readers not residing in North America.

These issues are minimal, however, and to be expected with edited books seeking to coalesce authors with various perspectives and expertise. CAMS covers quite a bit of ground, dealing as it does with the immense discipline of media studies and the novel realm of vegan theory. In collecting works of varying levels of inquiry, authorial background, and methodology, this text weaves an action-oriented but theoretically grounded approach that intrigues critical thought. Critical Animal and Media Studies initiates newcomers and challenges seasoned intellectuals. Despite its focus on Anglo-American culture, most of the research presented has an international appeal and invites future contributions from non-Western spaces. As the first of its kind, it is mandatory reading for critical media scholars who take interest with exploring systems of oppression and the full reach of intersecting experiences. For the ethical author, committed activist, and engaged journalist, this book belongs on the shelf.

Corey Lee Wrenn Monmouth University, USA

\section{Note}

1. Capitalized to emphasize the minority group status of other animals.

\section{References}

Adams C (2015) The Sexual Politics of Meat. New York: Bloomsbury Publishing. 
Freeman C (2016) This little piggy went to press: the American news media's construction of animals in agriculture. In: Almiron N, Cole M and Freeman C (eds) Critical Animal and Media Studies: Communication for Nonhuman Animal Advocacy. New York: Routledge, pp. 169-184.

Malamud R (2016) Looking at humans, looking at animals. In: Almiron N, Cole M and Freeman C (eds) Critical Animal and Media Studies: Communication for Nonhuman Animal Advocacy. New York: Routledge, pp. 154-168.

Nibert D (2003) Humans and other animals: sociology's moral and intellectual challenge. International Journal of Sociology and Social Policy 23(3): 4-25.

Peggs K (2013) The 'animal-advocacy agenda': exploring sociology for non-human animals. The Sociological Review 61(3): 591-606.

Sassatelli R (2011) Interview with Laura Mulvey: gender, gaze and technology in film culture. Theory, Culture \& Society 28(5): 123-143.

Wrenn C (2013) Resonance of moral shocks in abolitionist animal rights advocacy: overcoming contextual constraints. Society \& Animals 21(4): 379-394.

Wrenn C (2016) A Rational Approach to Animal Rights: Extensions in Abolitionist Theory. New York: Palgrave Macmillan. 